\section{Transcatheter embolization in treatment of congenital coronary artery aneurysm}

\author{
Ming-Fong Chen, $\mathrm{MD},{ }^{\mathrm{a}}$ Kuo-Liong Chien, $\mathrm{MD},{ }^{\mathrm{a}}$ \\ Yvk-Ming Tsang, MD, ${ }^{b}$ Chiau-Suong Liau, MD, ${ }^{a}$ and \\ Yuan-Teh Lee, MD ${ }^{\text {a }}$ Taipei, Taiwan
}

Congenital coronary artery aneurysm and coronary arteriovenous fistula are two rare conditions. ${ }^{1-3}$ An interesting case of a congenital coronary artery aneurysm that drained to a coronary arteriovenous fistula is presented. The aneurysm was successfully treated by transcatheter embolization with a complex helical fibered platinum coil. To the best of our knowledge this is the first case report of such an aneurysm treated by artificial embolization.

A 52-year-old man was admitted with a 1-year history of occasional chest tightness. His coronary risk factors included family history, male sex, sedentary lifestyle, and age. The result of physical examination was unremarkable. Blood pressure was $120 / 76 \mathrm{~mm} \mathrm{Hg}$. The pulse rate was 72 beats/min, with regular beat. A chest $x$-ray film and a resting electrocardiogram were normal. A treadmill exercise test with the standard Bruce protocol showed a negative result. The exercise duration was 8 minutes without significant changes. Echocardiography and all blood chemistries were normal. No oxygen step-up occurred during cardiac catheterization. Left ventriculography showed normal chamber size and wall motion. Select coronary arteriograms showed a patent right coronary artery. However, the left coronary artery had a saccular type aneurysm $(1.2 \times 1.1 \times 1.3 \mathrm{~cm})$ rising from a branch of the left anterior descending coronary artery (Fig. 1, left). The efferent vessel of the aneurysm connected to a coronary arteriovenous fistula originating from the left main coronary artery, which drained to the left pulmonary artery. To prevent sudden death from aneurysm rupture, treatment of such a condition was considered mandatory. A 7F JL4 guiding catheter (Cordis) for coronary angioplasty was put to the orifice of the left coronary artery through the right femoral artery. A $3 \mathrm{~F}$ infusion catheter (Target Therapeutics) was introduced into the neck of the aneurysm via a steerable 0.016-inch guide wire. The guide wire was then removed. A $2 \mathrm{~mm} / 10 \mathrm{~mm}$ complex helical fibered platinum coil (Target Therapeutics) was pushed to the neck of the aneurysm by a coil pusher (Target Therapeutics), but high blood flow pushed the coil into the aneurysm. Another 3

From the aDepartments of Internal Medicine (Cardiology) and ${ }^{\mathbf{b}}$ Radiology National Taiwan University Hospital.

Reprint requests: Ming-Fong Chen, MD, Department of Internal Medicine (Cardiology), National Taiwan University Hospital, 7, Chung-Shan South Rd., Taipei, 10002, Taiwan.

AM HEART J 1996;131:396-7.

Copyright (C 1996 by Mosby-Year Book, Inc.

$0002-8703 / 96 / \$ 5.00+0 \quad \mathbf{4 / 4 / 6 8 0 6 1}$ $\mathrm{mm} / 30 \mathrm{~mm}$ coil was put in place. The distal portion of the coil was put into the aneurysmal sac, and the proximal half was put in the afferent vessel. Follow-up angiograms showed the aneurysm as gradually nonvisualized. Approximately 15 min later the whole aneurysm and the efferent vessel had virtually no flow (Fig. 1, right). The coronary arteriovenous fistula was not treated because it had no hemodynamic significance. No complications occurred. Follow-up has been uneventful for 10 months.

Coronary artery aneurysm and coronary arteriovenous fistula are detected with increasing frequency through the advent of coronary arteriography. These conditions are found in $1 \%$ to $2 \%$ and $0.31 \%$, respectively, in patients who undergo coronary arteriographies. ${ }^{1-4}$ In adults more than half of the aneurysms are atherosclerotic in origin. In most cases the fistulae are small and without significant shunt, and the patient remains without symptoms. In the presence of large shunts normal coronary trees may not be clearly visualized because of the "steal" effect of the fistula. Congestive heart failure may develop, especially during later life. The coexistence of these two anomalies is unusual. This patient had a fully visualized left coronary artery and no evidence of heart failure or oxygen step-up, which is compatible with a small shunt.

Cardiac catheterization with selective coronary angiograms is the best modality for complete diagnosis of these two diseases, especially for the delineation of the distal drainage site. ${ }^{1,3,4}$ Other diagnostic procedures such as two-dimensional Doppler echocardiography with color flow mapping can accurately evaluate some of the anatomic features. ${ }^{5}$ However, these examinations were of no value in our case. The most likely cause of the aneurysm in this patient would seem to be congenital. No history of trauma or clear history of Kawasaki disease was reported. Other workups for connective tissue disease and arteritis were unrevealing. It is interesting that the efferent vessel of the aneurysm did not drain to the myocardium, as is usual. Instead, it connected to a coronary arteriovenous fistula. This manifestation gave the chance of artificial embolization without risk of iatrogenic myocardial infarction. Transcatheter embolization has been used in the treatment of various diseases of the heart and elsewhere in the body. ${ }^{6}$ This therapeutic modality provides precise and effective occlusion of the target vessel, resulting in less myocardial damage, avoiding operative risks an ensuring a shorter hospital stay.

\section{REFERENCES}

1. Barettella MB, Bott-Silverman C. Coronary artery aneurysms: an unusual case report and a review of the literature. Cathet Cardiovasc Diagn 1993;29:57-61.

2. Aufiero TX, Campbell DB, Waldhausen JA. Coronary artery aneurysms. Am Coll Cardiol Curr J Rev 1994;3:48-51.

3. Liberthson RR, Sagan K, Berkoben DP, Weintraub RM, Levine FH. Congenital coronary arteriovenous fistula: report of 13 cases, review of the literature and delineation of management. Circulation 1979;59:84454 . 


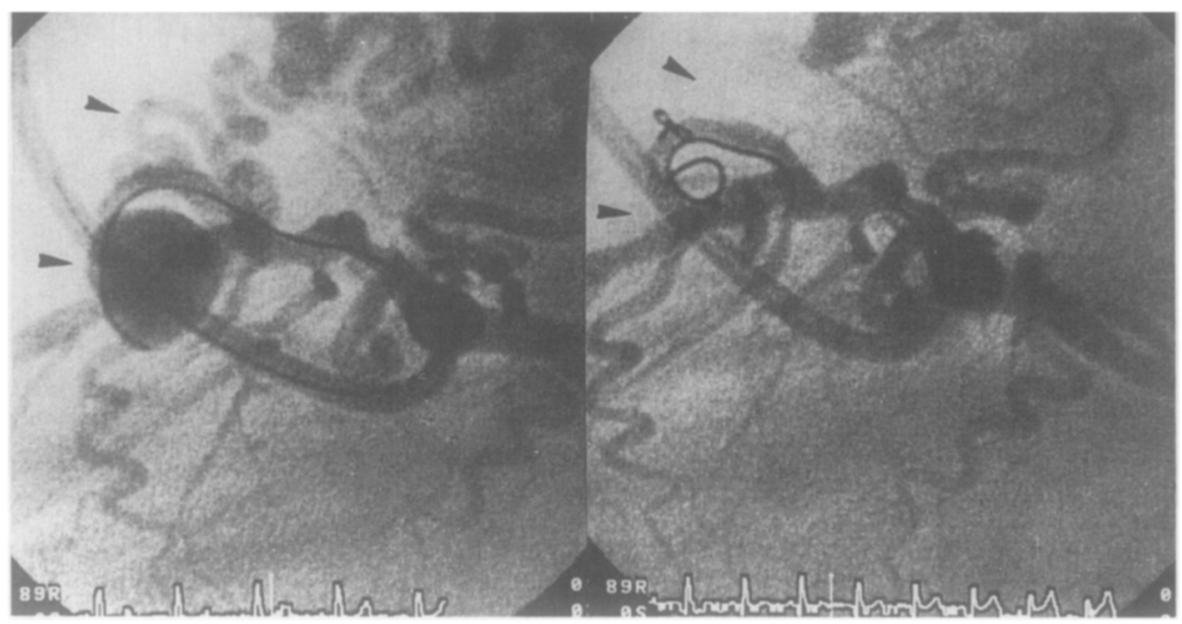

Fig. 1. Saccular type coronary artery aneurysm is in lateral projection. Aneurysm arises from branch of left anterior descending coronary artery (left). Efferent vessel of aneurysm connects to coronary arteriovenous fistula originating from left main coronary artery, which drains to left pulmonary artery. Aneurysm and efferent vessel (arrows) cannot be seen after coil embolization (right).

4. Wright WP, Alpert MA, Mukerji V, Santolin CJ. Coronary artery aneurysms: a case study and literature review. Angiology 1991;42:672-9.

5. Friedman DM, Rutkowski M. Coronary artery fistula: a pulsed Doppler/two-dimensional echocardiographic study. Am J Cardiol 1985; 55:1652-5.

6. Reidy JF, Anjos RT, Qureshi SA, Baker EJ, Tynan MJ. Transcatheter embolization in the treatment of coronary artery fistulas. J Am Coll Cardiol 1991;18:187-92.

\section{Left ventricular and aortic valve thrombosis caused by polycythemia rubra vera successfully treated with streptokinase}

\author{
Shukri Al-Saif, MB (Lon), MRCP (UK), ${ }^{\text {a }}$ \\ Rajindra P. Bhat, MD, DM (Cardio), ${ }^{a}$ \\ Ahmed Hijazi, MD, DM, CES (Cardio), ${ }^{a}$ \\ Ahmed Al-Faraj, MD, C-ARBIM, a and \\ Ismail Quadri, $\mathrm{MD}, \mathrm{PhD}^{\mathrm{b}}$ Dammam, Saudi Arabia
}

Left ventricular and left atrial thrombi are common and may result in systemic embolization. Prophylactic anticoagulation is of paramount importance in the presence of a predisposing cardiac lesion. ${ }^{1}$ In spite of this, some patients do not achieve a therapeutic level of anticoagulation and are therefore at risk of thrombosis. In addition, patients are in de novo condition with established thrombi even

From the aDivision of Cardiovascular Medicine, Medical Oncology, and

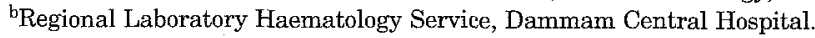
Reprint requests: S. AI-Saif, MB, MRCP, P.O. Box 8606, Dammam 31942, Saudi Arabia.

Av HEART J 1996;131:397-9.

Copyright (C) 1996 by Mosby-Year Book, Inc. $0002-8703 / 96 / \$ 5.00+0 \quad 4 / 4 / 68059$
Table I.

$\begin{array}{ll}\text { Hemoglobin } & 18.4 \mathrm{gm} / \mathrm{dl} \\ \text { Hematocrit } & 61.6 \% \\ \text { White blood count } & 37.55 \times 10^{9} \mathrm{~L} \\ \text { Platelets } & 999 \times \mathbf{1 0}{ }^{9} \mathrm{~L} \\ \text { Bone marrow } & \text { Hypercellular bone marrow on } \\ & \text { aspiration and biopsy involv- } \\ & \text { ing all three cell lines. Palli- } \\ & \text { sading of megakanycytes. De- } \\ & \text { pleted iron stores. Increased } \\ & \text { reticulin content. } \\ \text { Oxygen saturation } & \text { On room air) -96.2\% } \\ \text { Leukocyte alkaline } & 179 \text { (reference range 30-100) } \\ \text { phosphatase score } & 14.9 \text { seconds (control 11.5 sec- } \\ \text { Prothrombin time } & \text { onds) } \\ \text { Partial thromboplas- } & 31.5 \text { seconds (control 26 sec- } \\ \text { tin time } & \text { onds) } \\ \text { Antithrombin III } & \text { Normal } \\ \text { Lupus anticoagulant } & \text { Negative }\end{array}$

when they undergo adequate anticoagulation..$^{2,3}$ Heparin is the standard treatment for these patients. ${ }^{4}$ Patients with thrombosed prosthetic valves and left ventricular thrombi have been safely and successfully treated with thrombolytic therapy. ${ }^{5,6}$ This report describes the use of such therapy in a patient with thrombi in the left ventricle and on the aortic valve caused by polycythemia rubra vera.

A 60-year-old man was admitted because of sudden severe abdominal pain. He was found to have congestive heart failure, hypertension, and possible polycythemia vera because of the laboratory findings detailed in Table I. Before being admitted to the hospital, he had had an unwitnessed episode of loss of consciousness lasting 10 minutes with subsequent total recovery. Clinical and 